\title{
The Language of Women's Pain: Ideology and Critical Cultural Competencies in Pain Literacy
}

\author{
Mary Anne Taylor ${ }^{1}$ and Elizabeth M. Glowacki ${ }^{2 *}$ \\ ${ }^{1}$ Department of Communication Studies, Emerson College, Boston, MA, United States, ${ }^{2}$ Department of Communication \\ Studies, Northeastern University, Boston, MA, United States
}

This manuscript is concerned with a key tension in health communication: How women's pain is rhetorically constructed and culturally consumed. To date, there has been much research devoted to communicating the language of pain, rather, pain's inexpressibility (Scarry, 1985), as well as the construction of health narratives from private pain into public action (Kimball, 2000). Building on that literature, we make a rhetorical turn, and argue for a more critical rhetorical approach to pain literacy. To that end, the primary goal of this essay is to explore the rhetorical nuances and ideological limitations in pain literacy, from the point of when pain is expressed to how that expression is perceived. Through a critical cultural lens, we critique dominant narratives of pain, and argue for an intersectional

OPEN ACCESS

Edited by: Iccha Basnyat, James Madison University, United States

Reviewed by: Dyah Pitaloka,

University of Sydney, Australia Xiaoman Zhao,

Renmin University of China, China

*Correspondence:

Elizabeth M. Glowacki

e.glowacki@northeastern.edu

Specialty section:

This article was submitted to Health Communication,

a section of the journal Frontiers in Communication

Received: 01 October 2019 Accepted: 11 May 2020

Published: 17 June 2020

Citation:

Taylor MA and Glowacki EM (2020)

The Language of Women's Pain: Ideology and Critical Cultural

Competencies in Pain Literacy.

Front. Commun. 5:36.

doi: 10.3389/fcomm.2020.00036 heuristic of rhetorical care that promotes cultural competency and awareness to bridge gaps in the expression and perception of pain literacy.

Keywords: pain literacy, rhetorical care, health rhetoric, race, cultural competencies

\section{INTRODUCTION}

In January 2018, Serena Williams, arguably the greatest and most recognizable tennis player in the world, especially in women's tennis, shared with Vogue Magazine (Haskel, 2018), and in an HBO (HBO, 2018) documentary, that she nearly died, twice, after giving birth to her daughter. She experienced an all too familiar statistic for Black women post childbirth (CDC, Surveillance), a pulmonary embolism, or blood clot in the lungs. Although the threat of the condition is horrifying enough, what is most telling for the purposes of this essay, was that one of the most famous women in the world expressed pain and fear of early clotting symptoms post-delivery, yet, the delay in her care was almost fatal. Serena Williams says she pleaded with doctors for hours to address her pain, because as no stranger to blood clots, and understanding the severity and necessary immediate attention, she knew she had to move fast, especially if she were ever to play tennis again. As a world-class athlete, she knows her body, and knows how to communicate for her needs. She knew exactly what tests to request, exactly the progression from diagnosis to danger zone, yet, in her own words "Doctors would not listen to me," and later, in an interview with BBC (Fuller, 2018) "Doctors aren't listening to us [Black women]."

This pop cultural anecdote of Serena Williams is only one of many recent mediated examples that sheds light on a larger phenomenon: a mystification of women's pain, which leads not only to a lack of agency for women in pain, but also an articulation gap between pain expression and pain perception. Such a communication gap has led to misdiagnoses and delayed treatment for women whose expressions of pain are misunderstood or overlooked (Hoffmann and Tarzian, 2001). As a launching point for discerning pain expression and pain perception, we define pain literacy as it is rooted in Scarry's (1985) framework, where pain expression is the tension between the 
pain humans feel, then the articulation of that feeling to an audience; pain perception is how the receiver of that information, presumably a health care provider, responds to that communicative act. Scarry argues that this continuum from expression to perception is one of the most difficult semiotic undertakings of human language. While there are many limitations in pain articulation, we argue that one contributing factor to this gap is ideology, which is to say, a lack of attention to negotiating power competencies around the critical cultural identifications of race and gender. When we say ideology, we are invested in how marginalized voices challenge status quo normative narratives of a power structure. We situate and define normative health communication literature as a source driven by white-cis-heteromasculine perspectives, that are inherently exclusionary of marginalized populations outside of that norm. For the purposes of our essay, we are concerned specifically with the rhetoric and language of Black women's maternal health. Thus, when we use the term marginalization moving forward, we mean the exclusion of Black women's voices in healthcare narratives.

For women, specifically Black women, attempts to communicate pain during initial interactions with care providers can be met with skepticism (Weir et al., 1996) or with a misbelief that pain is caused by emotional factors rather than biological ones (Elderkin-Thompson and Waitzkin, 1999). We contend that beyond emotional factors and a lack of patient trust or empathy, there is another factor contributing to care gaps for women: Ideological incompetence and dismissal-informed by racial bias (Chuck, 2018), whether implicit or overt.

We started with a cultural anecdote because we argue for a cultural shift; rather, how pain is rhetorically constructed for Black women. For the purposes and scope of this manuscript, we wanted to look specifically at language gaps in care for Black women because of the expressed advocacy from groups like Black Mamas Matter and growing communication literature addressing health campaigns combatting Black maternal mortality. More directly, this has been a health issue since the infancy of health communication, but is growing momentum in communities that want to tackle bias and racial gaps in the field. Building on the literature of pain expression (Scarry, 1985; Kimball, 2000; Bustan, 2016), we argue that a key factor in pain literacy goes beyond gaps in epistemology, or the language and vocabulary of pain, but is also an ideological endeavor, where women's pain narratives are disciplined or managed through normative health narratives. In other words, to address Black women's experiences with pain in a more meaningful way, we have to not only consider the language used to describe pain, but the structures in place that prevent the pain experiences of this marginalized group from being taken seriously. But first, we need to define two key terms used throughout this manuscript; first, ideology, which we see as power, who has it - who doesn't-and how it is used to further marginalize communities of historical oppression. The second term, "critical cultural competencies," is a sub-field in rhetorical studies within communication studies literature, where "cultural competency" is a term often used to define and interrogate conditions outside or opposed to normative rhetorics (Crenshaw, 1989; Berlant and
Warner, 2002). In the critical rhetorical community, difference is understood as rhetorical motivation through experience, agency, and autonomy that serves to challenge normative social, cultural, and political discourses.

As a launching point, we will first situate and define pain beyond embodiment, which is to say, pain as it relates to power and policy through an intersectional and critical race lens (Crenshaw, 1989). Then, employing rhetorical criticism as a theoretical and methodological lens (Campbell, 1963; Campbell et al., 2014), we advance "rhetorical care" as a speculative lens for closing ideological gaps in pain literacy. We then turn to congressional testimony around House Resolution 1318, a Congressional resolution titled "Preventing Maternal Mortality" in order to interrogate racial indifference. Finally, after unpacking the testimony through a descriptive and rhetorical analysis, we argue for a heuristic shift in pain narratives which breaks from normative discourses of pain that further marginalize women, especially women with racial and ethnic barriers to care.

\section{THE LANGUAGE OF PAIN}

Pain literacy, defined as the rhetorical life of pain expression to pain perception, is largely considered an epistemological function, rather how the language and vocabulary of pain are used to express and detect one's discomfort. According to Scarry (1985), there are two categories of pain research, material-read physical—and verbal-the expression of pain. More specifically, Scarry offers five features for the linguistic function of pain expression, including: (a) description of experience from those in pain; (b) individuals speaking for, or with, those in pain; (c) a physician's work, the McGill Pain Questionnaire for example; (d) courtroom language that assesses and establishes damages for those in pain; and finally; (e) literary representations of pain (1985, p. 6-10). Beyond these five criteria, our analysis extends on one additional criterion in pain comprehension: ideology, as it relates to a combination of power, influence, and historical oppression of marginalized groups, in our case, black mothers. The Scarry model shows how most pain assessment, literacy, and perception is epistemological, rather, concerned primarily with forming and creating a language and vocabulary of pain between sender and receiver. However, we know that the construction and application of language does not happen in a vacuum, but is informed by rhetorical and historical situations that allow for context and creation of new opportunities and barriers for articulation.

Critiques of Scarry (Bustan, 2016) take up concerns of epistemological gaps, which are largely linked to the private nature of one's experiential pain, and lack of ability to have that pain expressed or translated the way one intended. Bustan confirms, "pain and suffering are defined, on one hand, as predominantly private experiences, often making people feel lonely and misunderstood by others who cannot feel and therefore grasp what they are going through. On the other hand, these phenomena embody interactions among different modes of subjectivity (self/I-you-him-them), thus defining them as substantially intersubjective" (p. 365). Because causes of 
pain and experiences with pain can vary widely, it can be difficult for practitioners and loved ones to comprehend fully the scope, severity, and persistence of an individual's pain (Magid, 2000). Further, Magid (2000) defines pain as "a perception communicated through both language and nonverbal behaviors such as tears or agitation. As such, pain is intrinsically subjective and inaccessible" (p. 114). Viewing pain in this way (as a "perception") both validates and challenges an individual's account of the pain experience.

Bustan, in nuancing Scarry's perception and five criteria of expressibility, also calls for addressing gaps in pain literacy, specifically pain as a lived modality, rather "whether pain is visible or obscure, essentially mine or dependent on others, subjective or interpersonal... or continuous swings between the worlds." (p. 365). However, even this perspective is mostly interested in defining, and teasing out, linguistic functions of pain toward the goal and outcome of expressibility. There is an extensive body of work within the field of health communication defining health literacy (Sørensen et al., 2012), establishing best practices for improving health literacy (Batterham et al., 2016), and evaluating outcomes of health literacy-focused interventions (Gazmararian et al., 2010). However, very little has been done to refine the concept of health literacy to capture the nuances of pain literacy; that is, looking at the language used to define and respond to a pain experience while simultaneously considering the larger cultural and social mechanisms in place that quell the voices of marginalized patient groups. As noted above, much of the emphasis in this area has been put on measuring and evaluating expressions of pain; less has been done to examine not only reactions to pain, but the ideological grounds in which those reactions are formed.

With the field's pre-occupation of language deficiencies, admittedly an important site for continued investigation, little agency is given to the rhetorical situation of not only how one feels pain, and expresses it, but importantly, how it is perceived based on assumptions of those in pain. To that end, we add to a criterion that Scarry flirted with, but never specifically took on, which we identify as ideology, rather, how power mechanisms serve to prop-up normative health narratives that often do not serve marginalized communities. Before introducing, and ultimately critiquing, dominant ideologies, we do wish to situate our critical rhetorical perspective in the existing health communication literature, drawing particular attention to existing gendered assumptions in pain literacy.

Although a substantial amount of work has been done looking at descriptions of pain within a clinical, patient-provider context (McDonald et al., 2000; Stanik-Hutt et al., 2001; Daly QuinlanColwell, 2009), less has been done to evaluate the language of pain within text-based and media contexts, which is to say, how pain is expressed and ultimately perceived. Understanding how individuals describe their experiences with pain both in and out of a medical setting can be useful for empowering patients and ensuring that pain is managed effectively (Chung and Lui, 2003; Tveiten and Meyer, 2009). Further, identifying differences between responses to pain experienced by men and women, especially women who face racial and ethnic barriers to care, can yield important implications for shifting the narrative of how women are viewed within the healthcare system.

The International Association for the Study of Pain (National Institutes of Health, 2019) defines pain as "an unpleasant sensory and emotional experience associated with actual or potential tissue damage, or described in terms of such damage." Pain is the most prevalent reason for seeking medical help, it is a subjective experience, and afflicts more Americans than heart disease, cancer, and diabetes combined (National Center for Complementary Integrative Health, 2019; National Institutes of Health, 2019). The issue of pain management has garnered even more attention in recent years with the opioid epidemic and rise in opioid-related deaths as efforts to provide alternative and less addictive forms of pain medications have increased (McGinley, 2018; Centers for Disease Control Prevention, 2019a). Initiatives like the United States Food and Drug Administration's (FDA) "Voices of the Patient" provide a platform for patients of chronic pain to share their stories and provide input on the challenges associated with finding effective methods of pain management (United States Food Drug Administration, 2019). Efforts such as these are helpful for creating spaces in which members of the public are seen as "experts" because of their own, unique experiences with navigating within the healthcare system in an attempt to find pain relief. However, more work needs to be done to create space and opportunity for marginalized voices to share their experiences of how their embodiments of pain are viewed and reacted to.

With regard to gender differences and biomedical outcomes, women have been less likely to be referred for cardiac catheterization (Schulman et al., 1999), to undergo coronary bypass surgery despite having equal or greater cardiac impairment as men (Steingart et al., 1991), to be sent to sleep laboratories for addressing symptoms associated with sleep apnea (Larsson et al., 2003), and to be referred for treatment of attention-deficit/hyperactivity disorder (ADHD) symptoms by teachers (Sciutto et al., 2004).

While it is true that there are biological differences between males and females that impact the onset and progression of some diseases (Buvinic et al., 2006), life expectancy rates (Murphy et al., 2018), and responses to certain kinds of drugs (Zopf et al., 2009), there is also evidence to suggest that expressions of pain from women are viewed differently which has led to women not being taking as seriously when describing or seeking help for their pain (Hoffmann and Tarzian, 2001), thus receiving an incorrect treatment dose (Weisse et al., 2003).

Perhaps of greater concern, is the notion of diagnostic delays which occur when there is a delay between the onset of symptoms that a patient experiences in a diagnosis (Selvam Paramasivam et al., 2017). From the Serena Williams example that started this essay, and in Kira Johnson's story below, the time from expressed pain to diagnosis is critical, and can be fatal if pain management is not addressed with immediacy. Female patients are more atrisk for experiencing diagnostic delays (and thereby delayed treatment) for multiple cancers including bladder, colorectal, lung, head and neck, gastric, and lymphoma (Din et al., 2015), endometriosis (Husby et al., 2003), and tuberculosis (Karim et al., 2007); even though female patients, on average, make more visits 
to their primary care physicians than men do (Bertakis et al., 2000). Beyond Scarry's initial five criteria for pain expression, this discrepancy suggests that there are speculative barriers to communication in place that contribute to delayed diagnoses and the enactment of treatment plans. We argue that discrepancy is an ideological limitation.

Additionally, it is important to consider the language used by individuals experiencing pain and how this might shape their perception of reality when it comes to living with pain. Strong et al. (2009) found that women used more graphic language, sensory words (e.g., "throbbing," "sharp," "stabbing"), and similes than men when describing their pain. Women also identified more mental images and used more words in general when describing their pain experiences (Strong et al., 2009). These authors theorize that this may be attributed to differences between men and women in socially and culturally learned responses to pain, such that men are traditionally expected to remain stoic in the face of pain and therefore, possess a smaller lexicon of pain descriptors (LeResche, 2011). To that end, recognizing and challenging the influence of hegemonic narratives in medical and public health spaces can be useful in devising more effective and empowering ways for exploring gaps in the pain literacy literature. Expanding on the gaps in the language of women's expressed pain, and in turn perceived pain in health communication contexts can perhaps offer language functions that do not discipline gender or skew toward dominant hegemonic narratives; thus, offering a more inclusive language model for pain management initiatives.

\section{CULTURAL COMPETENCIES IN HEALTH COMMUNICATION: RACE AND IDEOLOGY}

From the literature above, we can see some key take-aways from those addressing gendered gaps from pain expression to pain perception. First, an acquiescence that patients and physicians need to be using similar vocabularies to communicate needs and responses. Second, that the experiential reality of the patient and their expressed pain is perceived as a reflection of that reality. To that end, we argue that an inherent criteria for that reflection goes beyond epistemology, and is indeed ideological, meaning, shaped by rhetorical situations of identity and experience (Crenshaw, 1989) as it is defined and disciplined by dominant health narratives that can't or don't account for power gaps in the research of medical care. A critical cultural lens is necessarily fluid in order to adapt to how history has shaped cultural awareness and competencies of gender, race, class, and sexuality (Berlant and Warner, 2002). Following, we argue that there are ideological gaps in expressibility, inherently because the narrative arcs of pain literacy are not critical-which is to say-dominant health narratives do not engage with the lack of representation of traditionally marginalized communities, and how that perceived reality reinforces status-quo approaches to care. It follows then, that either explicitly or implicitly, health gaps are exacerbated and even deadly because of othering, effectively stripping visibility and agency from marginalized groups. From the earlier examples, would Serena Williams have been treated differently if she were white? We can't know, but the point here is that we can speculate, with a solid foundation in historical discrimination (Roeder, 2019) that race and the lack of articulation about race, is a factor, or should be, in understanding and studying the language of women's pain, how it is initially expressed, then medically perceived and comprehend, and ultimately treated.

Health communication literature continues to grow in studies for critical communities, including addressing transgender gaps in access and visibility (Perez-Brumer et al., 2018), health disparities and discrimination in the LGBT+ community (Harvey and Housel, 2014), and poverty invisibility (Redman, 2010). Critical communities are defined here as counter-publics often pushed to the margins of public sphere and normative comprehension of healthcare, often because marginalized communities are seen as antagonistic to hegemonic status-quo discourses of power. When we say critical agencies, there is a breadth of possibility, and multiple directions the literature could expand; however, for the sake of specificity and a focused scope for this manuscript, our rhetorical analysis looks at an example of pain expression from the ideological lens of race and ethnicity, in the case of Black women and Black maternal mortality post childbirth.

We know that there are material health consequences to patient care rooted in racism and discrimination-from racial disparities in pain prescription delivery (Tamayo-Sarver et al., 2003) to the condition of weathering (Geronimus, 2003) where African Americans experience the literal and structural weight of health conditions brought on by physical and psychological consequences from slavery and centuries of oppression in the United States. With those medical and health communication perspectives in mind, we ground our rhetorical analysis through a critical race lens (Crenshaw, 1989) in order to assess and perhaps intervene in pain literacy gaps tied to race and gender incompetence. To explore and highlight the ideological gaps in pain expression and perception through a lens of critical race studies, first, we need some historical and rhetorical context. Medical and health disparities, and the African American health experience are inextricably linked to American slavery (Barr, 2010). Structural oppressions were perpetuated through government policies and legislation following the Civil War and executed through Jim Crow reconstruction laws. In the medical community, discrimination and marginalization were exacerbated through experiments like sterilization of Black women, eugenics theories, and the Tuskegee syphilis project (Washington, 2006; Barr, 2010). Very few medical schools, hospitals, or care facilities accepted African Americans for formal medical schooling and training, and with the effects of white institutions not accepting Black applicants and the Flexner (1910) closing five of seven Historically Black (HBCU) medical schools, there was little to no access or upward mobility for African American physicians in the late 19th and early 20th centuries. As a consequence, not only was there a lack of representation to build epistemological functions of the African American health experience, but the institutional racism made health disparities inherently political and ideological (Arrington, 2015). This is to say that the inequities, lack of access, and structural oppressions explicitly de-limited health narratives for the African American 
community, and as a direct result from those material realities, the gaps in contemporary health management are not just linguistic, but cultural gaps in awareness and competencies of communities defined by difference.

Arrington argues (2015), two sources of injury remain intact from the aforementioned historical oppressions; the first, a collective distrust of health professionals in the African American community, which can certainly affect expressions of trauma and pain, and the second, a material and lasting violence committed by the health community, which created a suspicion that health professionals were using medicine to intentionally keep African Americans powerless (p. 5). A key take-away here, in addressing contemporary ideological gaps in pain literacy, is a cultural awareness that the legacy of exclusion and disciplining of the African American health experience silenced agency. To that end, whether implicit or explicit, dominant narratives are formed around in-groups, which subsequently provide for the erasure of experience, identity, and unique challenges of the marginalized out-groups.

So, how do we work to close those ideological gaps in gendered and racial health narratives? The call is fairly specific by Barlow and Dill (2018) who write to "re-imagine" holistic Black women's health through an intersectional feminist lens; their call: "confront the epistemic violence of erasure and silos that minimize the voices, expertise, and ways of knowing of interdisciplinary, transdisciplinary, and antidisciplinary scholars," (p. 2) and we would add here, health scholars and practitioners. As an operational and speculative lens to address these ideological gaps and lack of cultural competencies, we advance rhetorical care, rather, care as a bridge from private expressions of pain, to how pain is perceived, and managed publicly.

\section{OPERATIONALIZING PAIN LITERACY AS RHETORICAL CARE}

Care-as an operational theory-is largely attributed to Carol Gilligan's perspective found in, In a Different Voice (1982), and later, expanded into political and social theories by Tronto (1993, 2013) and Fisher and Tronto (1990). For Gilligan, a "different voice" is defined as privileging unique lived experiences of women, because "the way women talk about their lives is of significance, that the language they use and the connections they make reveal the world that they see and in which they act" (p. 2). Gilligan's care work developed out of a curiosity of the disconnection between men's and women's voices when they described, rather expressed, themselves in their own lived experience. Gilligan was writing from a social psychological lens, where in this literature, men's voices were ascribed public embodiment, and women's voices were relegated to a private sphere, and importantly, there was no bridge between the public and private. More than situated in a private sphere, for Gilligan (1982), women's descriptions of their embodiment were not listened to or taken seriously if there was no outcome our materiality realized outside of the private sphere. Gilligan, then, was committed to closing this binary, particularly in reproductive healthcare. More specifically, her concern was how women's voices, when describing their bodies, could be privileged in discourses of maternal health.

Gilligan's work was unapologetically essentialist in nature because it privileged the differences that women experienced biologically and learned culturally. Although inherently exclusionary, so consequently critiqued throughout feminist rhetoric (Tronto, 2013); her framework provides an epistemological lens for privileging and centering the voices of women in health communication. Rather, as she argues, "the difficulty women experience in finding or speaking publicly in their own voices emerges repeatedly in the form of qualification, where a public assessment and private assessment are fundamentally at odds" (Gilligan, 1982, p. 16). That qualification contributes to gendered binaries between private expressions and public perceptions of pain literacy.

Because early feminist interventions of care were embedded and theorized within psychology, care was contextualized as the motivation of the actor being studied (Woman v. Man), and feelings of care were shaped based on experiential understandings. Fisher and Tronto (1990) and Tronto (1994, 2013) brought care into communication and political literature by claiming care was tied not only to the actor, but the action [Act] of women's lives, particularly as that act played out in a public sphere. Introducing a new discourse for discussing gender in a public sphere, Tronto (2013) argues that we must revoke the inherent public/private split of care, specifically as it is positioned and privileged in the private. In an explanation of a public (read policy-governance) and private divide in relationship to care, Fisher and Tronto (1990) argue.

In this bifurcation, men's motivations lead them to behave purposively in the male sphere, which encompasses public matters, legal rights, paid labor, and formal relations. Women's motivations lead them to care in the female sphere, which encompasses private matters, familial duties, unpaid labor, and personal relationships. Because this bifurcation both stresses women's caring motivations and makes women's caring work relatively invisible, caring remains a mystified and oppressive concept (p. 36).

Many scholarly critiques of Gilligan were concerned that if care was essentialized toward privileging a woman's experience, government policies and legislation would continue to exclude the voices of women. However, what is important, here, is that Gilligan did not just give an epistemological function and method, she turned toward ideological implications in health disparities. Her research expanded on gendered notions of human development through life-cycle theory, meaning how people (for Gilligan, women) voice and shape their experiences. Gilligan traced "moral linguistic conflicts" through three case studies in reproductive healthcare. In the end, she contends that an ethic of care, although it may grow out of victimization or sexism, can be harnessed as empowerment through difference, and used to challenge hegemonic limitations.

Gilligan's perspective was tied to a feminist perspective rooted in the primary assumption that gender matters as a criterion for understanding what voices are being silenced, and what structures are responsible for the silencing. For Gilligan, equality 
was only attainable if the experiences of women were as privileged [if not more in policy debates like reproductive health] as the masculine experience. To that end, the only way to challenge exclusion, is to privilege the strength of the marginalized identity and voice, because as Gilligan argued, it is through the morality of care (1992) that women have significant advantages and training because of their systemic oppressions, where men do not.

As a launching place from Gilligan's ideological turn of care, we concede here that the personal is political. Fisher and Tronto show that "caring about" is a process in which "we select out and attend to the features of our environment that bear on our survival and well-being" (p. 41). Traditional notions of care, as they are theorized by Gilligan were a relational concept tied to the motivation of the actor. Tronto theorizes care beyond motivation, where the orientation of care is not only relational and tied to motivation of the actor, but also a practice where the act and maintenance of society is, in fact, care work. Rhetorical care, then, is a speculative lens of discovery to interrogate the motivation (actor) and orientation (act) in determining ideological intervention.

To define and operationalize a heuristic of care, we build from Tronto's initial four methodological elements of care work, which were: attentiveness, responsibility, competence, and responsiveness. The four elements advance a prescription where motivational care is a conscious understanding of how care work is communicated through four habits, which for Fisher and Tronto (1990) are defined as: caring about, or noticing the need to care; taking care of, or assuming responsibility for care; caregiving; and finally, care receiving. Situated within those habits of care, attentiveness is understood as recognition, responsibility as a political ethic, competence as credibility, and responsiveness as deliberation (Tronto, 2013). Tronto's elements “inform us as citizens, and direct us to a politics in which there is, at the center, a public discussion of needs, and hones appraisal of the intersection of needs and interest" (2013, p. 168). For Tronto, there is no political theory, explicitly or implicitly, that does not contain an account of care (2013, p. 25). Although a useful working method, the original four habits and elements are reduced to traditional tropes of limited democracy, rather liberalism, which is also inherently exclusive of marginalized voices. However, Tronto's resilience at the intersection of private needs and public interest, we find a useful lens for thinking through private expressions of pain and the audience perception of that pain.

Where Gilligan is limited in relegating care to the private sphere-pain expression-and Tronto is limited by the four elements only associated with the public-perceived pain-we offer rhetorical care as an ideological endeavor, with a primary assumption that the personal is political; therefore we need additional elements to bridge the gaps between expressibility and perception. To that end, we introduce rhetorical care, as an organic critical cultural speculative lens, and defined as having two criterion: First, rhetorical care is intersectional, meaning an awareness of how and why overlapping identities challenge dominant oppressive ideologies; and second, a necessary fluidity for how healthcare epistemology is shaped by hegemonic status quo narratives that inherently exclude and marginalize certain voices.

\section{A CASE FOR RHETORICAL CARE}

Rhetorical care, for our purposes in this manuscript, builds on Gilligan's notion of care through essentialized identity work and Tronto's political theory work to make a case for a shift in the way scholars, and health professionals engage with women's pain. The theoretical and practical understanding of care is relational. Gilligan saw this relational tendency through attachment to one's gender identity, and Tronto sees relational capacity through democracy and its limitations. We see rhetorical care as both: essentially gendered, and ultimately motivated by challenging hegemonic oppressions. Within that framework, then, rhetorical care argues that agents of power must consider the ideological context for excluded and marginalized voices, specifically the relational and historical context of women's lived experience. Finally, rhetorical care is a vehicle which does not argue for intervention through sameness, but difference, where cultural competencies and counter-ideologies must be considered in contemporary health narratives. This is to say, if race and gender are not considered as functions in pain literacy; there is no chance for meeting Scarry's call for closing gaps in pain expressibility.

In this section of the manuscript, we will look to witness testimony as a descriptive and rhetorical lens for offering a larger discussion about ideological gaps in Black women's experienced pain, and their perceived pain, largely from white perspectives of healthcare. On September 27, 2018, the Subcommittee on Health for the United States House of Representatives met on the House Resolution (HR) 1318: Preventing Maternal Mortality. The theme of the hearing became clear; although every population in the United States was affected by mother and infant mortalityin startling rates for a developed country-the more palpable and urgent testimony and congressional questioning was about Black moms, and the gaps in care for that specific community.

The subcommittee on health is made up of 32 members of Congress. The demographics of the committee are largely reflective of Congress as a whole-mostly male, and mostly white. The task of the House Resolution, if implemented, was better data and outcomes in reducing maternal mortality in the United States (US). There are three startling facts of maternal mortality: first, the United States has the highest mortality rate among all developed nations; two, while mortality is decreasing in comparative nations, it is increasing in the US; and three, and most importantly for this analysis, there are considerable racial and ethnic disparities in the US (Centers for Disease Control Prevention, 2019b). According to the CDC's Pregnancy Mortality Surveillance System, between 2011 and 2015, pregnancy related mortality ratios indicated that there were approximately 43 deaths per 100,000 live births for Black women, to 13 deaths per 100,000 live births for white women. At the beginning of the hearing, Congresswoman Jaime Herrera Beutler opened with a statement as a co-sponsor of HR 1318, testimony then began with Charles Johnson IV, founder of 4Kira4Moms, Stacey Steward, President of the March of Dimes; Dr. Lynne Coslett-Charlton 
from the American College of Obstetricians and Gynecologists, and Dr. Joia Crear-Perry, President of the National Birth Equity Collaborative.

Mr. Johnson began his testimony expressing to the committee the happiness he and Kira Johnson shared when the couple first learned she was pregnant for a second time. That expression was soon followed by his devastation-in his words-Kira was now a "mortality statistic" along with the $50 \mathrm{~K}$ women who had died of complications in childbirth since 2015. Noting that statistic, women of color (Centers for Disease Control Prevention, 2019b), regardless of income and education, like Kira, were three-four times more likely to die. According to the CDC and Harvard's Chan School of Public Health, holistic medical reasons for increased pregnancy related mortality, specifically the racial and ethnic disparities, remains unclear. We contend, like others (Black Women's Health Study, 2019) that the gap in care is beyond medical positioning, but perhaps also related to the epistemological and ideological gaps between a Black woman's expressed pain, and the perceived reality of that pain, particularly among white providers.

Kira Johnson was a marathoner, and as Charles describes her, mobile, active, and full of life. Kira did not suffer from any of the leading medical conditions associated with maternal mortality rates, including, hypertension, heart disease, diabetes, or blood conditions. On the day of her labor, there were no medical complications in anesthesia, or infection. For all intents and purposes, Kira Johnson was the picture of health. Below, are segments from Charles Johnson's testimony about Kira's experience (United States House of Representatives: Subcommittee on Health, 2018):

We went in for what was supposed to be a routine scheduled Csection on what was supposed to be the happiest day of our lives and we walked right into what was our worst nightmare. After delivering another perfect baby, I was sitting next to Kira by her bedside in the recovery room. That is when I first noticed blood in her catheter. I notified staff immediately. A series of test were ordered. Along with a CT scan to be performed "STAT." I understood "STAT" to mean the CT scan would be performed immediately.

Hours passed and Kira's symptoms escalated throughout the rest of the afternoon and into the evening. We were told by the medical staff at Cedars Sinai Kira was not a priority and we waited for her CT scan to be done... we waited for the hospital to act so she could begin her recovery. Kira kept telling me, "Charles, I'm so cold; Charles, I don't feel right." She repeated these same words to me for several hours.

After more than $10 \mathrm{~h}$ of waiting. After $10 \mathrm{~h}$ of watching my wife's condition deteriorate. After $10 \mathrm{~h}$ of watching Kira suffer in excruciating pain needlessly. After $10 \mathrm{~h}$ of begging and pleading them to help her. The medical staff at Cedars Sinai finally took action. As they prepared Kira for surgery, I was holding her hand as we walked down the hall to the operating room. Kira looked at me and said, "Baby, I'm scared." I told her, without doubt, everything was going to be fine.

The doctor told me I would see her in $15 \mathrm{~min}$. Kira was wheeled into surgery and it was discovered that she had massive internal bleeding caused by horrible medical negligence that occurred during her routine C-section. She had approximately 3 liters of blood in her abdomen. Kira died at 2:22 a.m. April 17, 2016. Langston was $11 \mathrm{~h}$ old.

In unpacking the testimony of Johnson, there is one clear takeaway-pain was expressed over, and over, and over-and ultimately was not perceived with any serious medical attention or even curiosity. A marathoner and the picture of health, explaining her discomfort, that "she was so cold," and with blood visually in her catheter, told over and over that she was not a medical priority. Given what we know about maternal mortality, particularly among Black women, what would it have taken for her to be a medical priority? As Mr. Johnson emotionally told this congressional committee that she was begging for her life, it seems apt to speculate, that although Kira Johnson explained that she knew her body, and that something wasn't right, those exclamations and expressions of pain were not perceived with urgency or immediacy.

A key take-away in this case of Kira and Charles Johnson, and one all too familiar as pointed out by Amnesty International's report 2010, mortality rates are much more than health conditions, or quality access to maternal health care, but also social barriers like racial discrimination. Like Johnson, Alia McCants of Harlem, who at New York's Mount Sinai Hospital, almost died post labor from hemorrhaging, also believes that race was a factor in her care (Chuck, 2018). McCants' states "from the social worker who was visibly surprised by my husband and me as black professionals having twins, from the lack of empathy to her pain, and rushing her out of the hospital" ... how much was the lack of care due to "because I was black." Another example, Jaymie Rivera-Clemente of Texas, who identifies as Black and Latina, describes lack of care ranging from outright dismissal, to the more subtle micro-aggressions of physician's offices; questions to RiveraClemente like "do all of your kids have the same father" (Chuck, 2018). Johnson, McCants, and Rivera-Clemente are not alone. According to a survey done in partnership with NPR, the Robert Wood Johnson Foundation, and the Harvard T.H. Chan School of Public Health, 32 percent of Black women surveyed reported that they have been discriminated against in physician's offices (Discrimination in America, 2017). Quoting a talk given by Ana Langar, the coordinator of Harvard's Women's Health Initiative at the Harvard Chan School of Public Health, Roeder (2019) cites, "Women-particularly those who are most vulnerable due to their race, age, or socioeconomic status-receive less attention overall for their health issues, compared to men." More specifically, Elizabeth Dawes Gay, of BlackMamasMatter.org, argues:

Those of us who want to stop black mamas from dying unnecessarily have to name racism as an important factor in black maternal health outcomes and address it through strategic policy change and culture shifts. This requires us to step outside of a framework that only looks at health care and consider the full scope of factors and policies that influence the black American experience. It requires us to examine and dismantle oppressive and discriminatory policies. And it requires us to acknowledge 
black people as fully human and deserving of fair and equal treatment and act on that belief (Roeder, 2019).

Following Johnson's testimony, Stewart of the March of Dimes followed with statistics and how a bill like this would close gaps. She also pointed out that this was a holistic issue where there is not a single answer for a single problem, building on Johnson's testimony stating:

\begin{abstract}
The causes of maternal mortality and severe maternal morbidity are diverse. They include physical health, mental health, social determinants, and much more. They can be traced back to the issues in our healthcare system including the quality of care as we just heard so passionately from Charles, systems problems, and of course the issue of implicit bias that exist in our healthcare system. They stem from factors in our homes, our workplaces, and our communities.
\end{abstract}

Dr. Raymond Cox, a former OB-GYN and now with "Volunteers in Medicine," is working to alleviate implicit bias in trainings, and in the language of care between doctors and patients. Dr. Cox states that he has seen implicit bias on every level of medical treatment and has witnessed patients treated differently because of race, offering "Doctors tend to spend less time and tend to assume that the Black or Latino patient isn't going to understand what we're talking about, and as a consequence, have a tendency to make decisions for that patient" (Chuck, 2018). Again, we have this explanation point on the fact that there are other factors at play beyond medicine.

The final testimony of the hearing was from Dr. Crear Perry, an obstetrician, and also a member of the American College of Obstetricians and Gynecologists. Her testimony was a follow up to her colleague's Dr. Charlton, who spoke of unique gains in unique state situations, like California that had a decreasing maternal mortality rate. Dr. Perry however added that although California is seeing fewer deaths among new mothers in the state, the deaths among Black women has increased. Dr. Perry's testimony takes dead aim at the ideological limitations of maternal health. She argues, "the legacy of a hierarchy of human value based on the color of our skin continues to cause differences in health outcomes, including maternal mortality. Racism is the risk factor-not Black skin. There is no "Black" "gene" (HR 1318 testimony). She then followed with her own narrative, where her now 22 years old son was born premature in a hospital named Confederate Memorial, and talked to the committee members about what was considered "normative" prejudicial behavior with her as the patient, and a medical resident at the time. In closing, Dr. Perry states-in tone-demands,

Ultimately, what Black women in the U.S. need is accountability. We need to know that our lives are valued. This accountability may be complicated, but government still has an obligation to act. Racism, classism and gender oppression are killing all of us, from rural to urban America.

This is not about intentions. Lack of action is "unintentionally" killing us. It is a human rights imperative. Throughout the bill, there is no mention of race, racism, or racial disparities. The inability to name this as a key focus to reduce RACIAL disparities in maternal mortality and morbidity will continue to exacerbate the problem. We must ensure that prevention efforts and resources are being directed toward the areas of greatest need and be willing to name the problem directly.

Much can be accomplished through improved monitoring and data collection. H.R.1318 is a tremendous step forward in showing that we do recognize... Yes, Black Mamas Matter.

Dr. Perry does not leave much to the imagination, and serves here to illustrate the gap that this manuscript has been negotiating; Dr. Perry points directly toward racism as a medical factor in addressing the gap in care between Black mothers and their health care providers.

\section{DISCUSSION}

We contend that voicing pain, rather, pain expressibility is more than an epistemological endeavor. Certainly, linguistic functionality is part of pain expression. As Scarry (1985) and Bustan (2016) would illustrate, certain "common practices" of language allow for and demand articulation between pain expression and perception. For example, if I say "my head hurts" there is a common practice on the continuum of expression-perception-treatment. The common perception would most likely result in "take a pill, it will pass." The idea of "common practice" is a normative communicative function in health communication, with normative conditions and expectations. But as we have shown throughout this essay, race-and othering because of race-challenges the normative, in that "common practice" is more challenging for underrepresented, often marginalized, and stigmatized populations. There is a gap in articulation-epistemological, and as we have argued, ideological.

To understand a holistic view of pain literacy, we have argued that there are ideological currents to explain gaps in pain care. Scarry gives us a launching point as she focused on the agency of pain, rather than physical pain, which was tautological, had agency; the person expressing pain, had agency. We too, are concerned with agency, but its limitations, which is to say, we have illustrated in these case examples, that there are also gaps in who has agency. As a result, it seems that we do not pay enough attention to the agency of perceived pain, rather, how cultural and racial competencies play a role in de-limiting agency for those who fall outside of normative conditions of pain articulation.

To that end, we introduced rhetorical care, as an intervention into the pain literacy literature housed in health communication, where the care lens strives to be intersectional, calling for a cultural awareness and competence that is epistemologically nuanced. We certainly acknowledge that there are many medical factors and variables in the cases of Kira Johnson, Alia McCants, Jaymie Rivera-Clemente, and even Serena Williams. What we hoped to introduce by expanding on these examples were gaps in language perceptions where race was a material and symbolic factor in each case. We are not medical professionals, and we can never know for sure what led to the all too common realities of each example introduced, but we argue as rhetorical and health communication scholars that race and gender must 
be considered as primary factors in negotiating the journey from pain expression to pain perception and ultimately, pain treatment. As mentioned above, diagnostic delays happen at a greater rate for women than men when women express pain (Selvam Paramasivam et al., 2017). Additionally, Hoffmann and Tarzian (2001) suggest that expressions of pain from women may not be taken as seriously when describing or seeking help for their pain. Finally, we would argue that from the lenses of Washington (2006), Barr (2010), and Arrington (2015), race is a factor when considering epistemological and ideological gaps in healthcare.

Specifically, to address bridging ideological gaps in pain literacy, which we see as the rhetorical life of pain expression to pain perception, we argued for a heuristic shift, defined as rhetorical care. Rhetorical care as it builds on Gilligan's (1982) notion of care through attachment identity work and Tronto's (2013) political theory work, we make the case for a shift in the heuristic of pain literacy. From a theoretical perspective, we build from and add to the four original elements of care by asserting that rhetorical care is intersectional, epistemologically nuanced

\section{REFERENCES}

Amnesty International (2010). Deadly Delivery: the Maternal Health Care Crisis in the USA. Available online at: https://www.amnestyusa.org/files/pdfs/ deadlydelivery.pdf (accessed September 21, 2019).

Arrington, J. (2015). The flexner report and the african-american health experience: black collective memory and identity as shaped by afrocultural trauma and re-membering. Vanderbilt Hum. Soc. Sci. 10, 1-8. doi: 10.15695 /vurj.v10i0.4063

Barlow, N. B., and Dill, L. J. (2018). Speaking for ourselves: reclaiming, redesigning, and reimagining research on black women's health. Meridians 16, 1-11. doi: 10.2979/meridians.16.2.03

Barr, D. A. (2010). Questioning the Premedical Paradigm Enhancing Diversity in the Profession a Century After the Flexner Report. Baltimore: Johns Hopkins University Press.

Batterham, R. W., Hawkins, M., Collins, P. A., Buchbinder, R., and Osborne, R. H. (2016). Health literacy: applying current concepts to improve health services and reduce health inequalities. Public Health 132, 3-12. doi: 10.1016/j.puhe.2016.01.001

Berlant, L., and Warner, M. (2002). Publics and Counterpublics. Cambridge: Press and City are MIT Press.

Bertakis, K. D., Azari, R., Helms, L. J., Callahan, E. J., and Robbins, J. A. (2000). Gender differences in the utilization of health care services. J. Fam. Pract. $49,147-152$

Black Women's Health Study (2019). Boston University Slone Epidemiology Center. Available online at: https://www.bu.edu/bwhs/ (accessed September 27, 2019).

Bustan, S. (2016). Voicing pain and suffering through linguistic agents: nuancing elain scarry's view on the inability to express pain. Subjectivity 9, 363-380. doi: $10.1057 / \mathrm{s} 41286-016-0007-5$

Buvinic, M., Médici, A., Fernández, E., and Torres, A. C. (2006). "Gender differentials in health," in Disease Control Priorities in Developing Countries, 2nd Edn, (New York, NY: Oxford University Press), 195-210. doi: 10.1596/978-0-8213-6179-5/Chpt-10

Campbell, G. (1963). The Philosophy of Rhetoric. Carbondale, IL: Southern Illinois University.

Campbell, K. K., Huxman, S. S., and Burkholder, T. A. (2014). The rhetorical act: Thinking, speaking and writing critically. Stamford, CT: Nelson Education.

Centers for Disease Control and Prevention (2019a). CDC Guidelines for Prescribing Opioids for Chronic Pain. Avaliable online at: https://www.cdc.gov/ drugoverdose/prescribing/guideline.html (accessed August 30, 2019). as language relates to race and cultural competencies, and argues that agents of power must consider the ideological context for marginalized communities, specifically in gendered and racial pain literacy gaps. From a material and applied perspective, we assert that pain literacy from a perspective of rhetorical care could expand on health professional trainings, such as implicit bias trainings, or provide a launching point for further data collection and testing for monitoring ideological gaps in care for marginalized communities, and ultimately serves to intervene and bridge those divides.

\section{DATA AVAILABILITY STATEMENT}

All datasets analyzed for this study are cited in the article/supplementary material.

\section{AUTHOR CONTRIBUTIONS}

All authors listed have made a substantial, direct and intellectual contribution to the work, and approved it for publication.

Centers for Disease Control and Prevention (2019b). Pregnancy Surveillance Mortality System. Avaliable online at: https://www.cdc.gov/reproductivehealth/ maternalinfanthealth/pregnancy-mortality-surveillance-system.htm (accessed September 5, 2019).

Chuck, E. (2018). How Training Doctors in Implicit Bias Could Save the Lives of Black Mothers. Avaliable online at: https://www.nbcnews.com/news/usnews/how-training-doctors-implicit-bias-could- save-lives-black-mothersn873036? icid=related (accessed December 22, 2019).

Chung, J. W., and Lui, J. C. (2003). Postoperative pain management: study of patients' level of pain and satisfaction with health care providers' responsiveness to their reports of pain. Nurs. Health Sci. 5, 13-21. doi: 10.1046/j.1442-2018.2003.00130.x

Crenshaw, K. (1989). Demarginalizing the intersection of race and sex: a black feminist critique of antidiscrimination doctrine, feminist theory and antiracist politics. Univ. Chi. Legal Forum. 140, 139-167.

Daly Quinlan-Colwell, A. (2009). Understanding the paradox of patient pain and patient satisfaction. J. Holist. Nurs. 27, 177-182. doi: 10.1177/0898010109332758

Din, N. U., Ukoumunne, O. C., Rubin, G., Hamilton, W., Carter, B., Stapley, S., et al. (2015). Age and gender variations in cancer diagnostic intervals in 15 cancers: analysis of data from the UK clinical practice research datalink. PLoS ONE 10:e0127717. doi: 10.1371/journal.pone.0127717

Discrimination in America (2017). Experiences and Views of African Americans. a Report in Partnership With NPR, the Robert Wood Johnson Foundation, and the Harvard T.H. Chan School of Public Health. Avaliable online at: https:// www.rwjf.org/en/library/research/2017/10/discrimination-in-america-experiences-and-views.html (accessed December 26, 2017).

Elderkin-Thompson, V., and Waitzkin, H. (1999). Difference in clinical communication by gender. J. Gen. Intern. Med. 14, 114-121. doi: 10.1046/j.1525-1497.1999.00296.x

Fisher, B., and Tronto, J. (1990). "Toward a feminist theory of caring," in Circles of Care (New York, NY: SUNY Press) 36-54.

Flexner, A. (1910). Medical Education in the United States and Canada: A Report to the Carnegie Foundation for the Advancement of Teaching. Retrieved from: http://archive.carnegiefoundation.org/publications/pdfs/elibrary/Carnegie_ Flexner_Report.pdf (accessed June 11, 2020).

Fuller, R. (2018). Serena Williams: Statistics on Deaths in Pregnancy or Childbirth Heartbreaking. BBC Broadcasting. Avaliable online at: https://www.bbc.com/ sport/tennis/43299147 (accessed September 22, 2019).

Gazmararian, J., Jacobson, K. L., Pan, Y., Schmotzer, B., and Kripalani, S. (2010). Effect of a pharmacy-based health literacy intervention and patient 
characteristics on medication refill adherence in an urban health system. Ann. Pharmacother. 44, 80-87. doi: 10.1345/aph.1M328

Geronimus, A. (2003). Deep integration: letting the epigenome out of the bottle without losing sight of the structural origins of population health. Am. J. Public Health 103(Suppl. 1), S56-S63. Avaliable online at: http://pascal-francis.inist. fr/vibad/index.php?action=search\&terms $=27728590$ (accessed December 22).

Gilligan, C. (1982). In a Different Voice: Psychological Theory and Women's Development. Boston, MA: Harvard University Press.

Harvey, V. L., and Housel, T. H. (2014). Health Care Disparities and the Lgbt Population. Avaliable online at: https://ebookcentral.proquest.com (accessed September 22, 2019).

Haskel, R. (2018). Serena Williams on Motherhood, Marriage, and her Comeback. Avaliable online at: https://www.vogue.com/article/serena-williams-voguecover-interview-february-2018?mbid=zr_serenawilliams (accessed September $22,2019)$.

HBO (2018). Being Serena. Avaliable online at: https://www.hbo.com/being-serena (accessed September 22, 2019).

Hoffmann, D. E., and Tarzian, A. J. (2001). The girl who cried pain: a bias against women in the treatment of pain. J. Law Med. Ethics 28, 13-27. doi: 10.1111/j.1748-720X.2001.tb00037.x

Husby, G. K., Haugen, R. S., and Moen, M. H. (2003). Diagnostic delay in women with pain and endometriosis. Acta Obstet. Gynecol. Scand. 82, 649-653. doi: $10.1034 / j .1600-0412.2003 .00168 . x$

Karim, F., Islam, M. A., Chowdhury, A. M. R., Johansson, E., and Diwan, V. K. (2007). Gender differences in delays in diagnosis and treatment of tuberculosis. Health Policy Plan. 22, 329-334. doi: 10.1093/heapol/czm026

Kimball, M. M. (2000). From "Ann O." to bertha pappenheim: transforming private pain into public action. Hist. Psychol. 3, 20-43. doi: 10.1037/1093-4510.3.1.20

Larsson, L. G., Lindberg, A., Franklin, K. A., and Lundba, B. (2003). Gender differences in symptoms related to sleep apnea in a general population and in relation to referral to sleep clinic. Chest 124, 204-211. doi: 10.1378/chest.124.1.204

LeResche, L. (2011). Defining gender disparities in pain management. Clin. Orthop. Relat. Res. 469, 1871-1877. doi: 10.1007/s11999-010-1759-9

Magid, C. S. (2000). Pain, suffering, and meaning. JAMA 283:114. doi: 10.1001/jama.283.1.114-JMS0105-2-1

McDonald, D. D., McNulty, J., Erickson, K., and Weiskopf, C. (2000). Communicating pain and pain management needs after surgery. Appl. Nurs. Res. 13, 70-75. doi: 10.1016/S0897-1897(00)80003-8

McGinley, L. (2018). FDA Pushes dor Development of Non-opioid Pain Medications. The Washington Post. Avaliable online at: https:/www.washingtonpost.com/ news/to-your-health/wp/2018/08/29/fda-pushes-for-development- of-nonopioid-pain-medications/?noredirect=on (accessed August 30, 2019).

Murphy, S. L., Xu, J., Kochanek, K. D., and Arias, E. (2018). Mortality in the United States, 2017. (Hyattsville, MD: National Center for Health Statistics Data Brief, 328).

National Center for Complementary and Integrative Health (2019). Pain. Avaliable online at: https://nccih.nih.gov/health/pain (accessed August 30, 2019).

National Institutes of Health (2019). Pain management. Avaliable online at: https:// report.nih.gov/nihfactsheets/viewfactsheet.aspx?csid=57 (accessed August 30, 2019).

Perez-Brumer, A., Nunn, A., Hsiang, E., Oldenburg, C., Bender, M., Beauchamps, L., et al. (2018). "We don't treat your kind": assessing HIV health needs holistically among transgender people in Jackson. Mississippi. PLos One 13:e0202389. doi: 10.1371/journal.pone.0202389

Redman, L. F. (2010). Outing the invisible poor: why economic justice and access to health care is an LGBT issue. Geo. J. Poverty L. Pol'y. 3, 451-460.

Roeder, A. (2019). America is failing it's black mothers. Harvard Public Health Magazine, Winter. Avaliable online at: https://www.hsph.harvard.edu/ magazine/magazine_article/america-is-failing-its-black-mothers/ (accessed August 30, 2019).

Scarry, E. (1985). The Body in Pain. New York, NY: Oxford University Press.

Schulman, K. A., Berlin, J. A., Harless, W., Kerner, J. F., Sistrunk, S., Gersh, B. J., et al. (1999). The effect of race and sex on physicians' recommendations for cardiac catheterization. N. Engl. J. Med. 340, 618-626. doi: 10.1056/NEJM199902253400806
Sciutto, M. J., Nolfi, C. J., and Bluhm, C. (2004). Effects of child gender and symptom type on referrals for ADHD by elementary school teachers. J. Emot. Behav. Disord. 12, 247-253. doi: 10.1177/10634266040120040501

Selvam Paramasivam, B. T., Chandran, P., Thayyil, J., George, B., and Sivakumar, C. P. (2017). Diagnostic delay and associated factors among patients with pulmonary tuberculosis in Kerala. J. Family Med. Prim. Care 6, 643-648. doi: $10.4103 / 2249-4863.222052$

Sørensen, K., van den Broucke, S., Fullam, J., Doyle, G., Pelikan, J., Slonska, Z., et al. (2012). Health literacy and public health: a systematic review and integration of definitions and models. BMC Public Health 25, 12-80. doi: 10.1186/1471-2458-12-80

Stanik-Hutt, J. A., Soeken, K. L., Belcher, A. E., and Fontaine, D. K. (2001). Pain experiences of traumatically injured patients in a critical care setting. Am. J. Crit. Care 10, 252-259. doi: 10.4037/ajcc2001.10.4.252

Steingart, R. M., Packer, M., Hamm, P., Coglianese, M. E., Gersh, B., Geltman, E. M., et al. (1991). Sex differences in the management of coronary artery disease. N Engl. J. Med. 325, 226-230. doi: 10.1056/NEJM199107253250402

Strong, J., Mathews, T., Sussex, R., New, F., Hoey, S., and Mitchell, G. (2009). Pain language and gender differences when describing a past pain event. Pain 145 , 86-95. doi: 10.1016/j.pain.2009.05.018

Tamayo-Sarver, J. H., Hinze, S. W., Cydulka, R. K., and Baker, D. (2003). Racial and ethnic disparities in emergency department analgesic prescription. Am. J. Public Health 93, 2067-2073. doi: 10.2105/AJPH.93.12.2067

Tronto, J. (1994). Moral boundaries: A political argument for an ethic of care. New York, NY: Routledge.

Tronto, J. (2013). Caring Democracy: Markets, Equality and Justice. New York, NY: New York University Press.

Tronto, J. C. (1993). Moral Boundaries: A Political Argument for an Ethic of Care. Psychology Press.

Tveiten, S., and Meyer, I. (2009). 'Easier said than done': empowering dialogues with patients at the pain clinic-the health professionals' perspective. J. Nurs. Manage. 17, 804-812. doi: 10.1111/j.1365-2834.2008.00921.x

United States Food and Drug Administration (2019). The Voice of the Patient: a Series of Reports From FDA'S patient-Focused Drug Development Initiative. Avaliable online at: https://www.fda.gov/industry/prescription-drug-userfee-amendments/voicepatient-series-reports-fdas-patient-focused-drugdevelopment-initiative (accessed August 30, 2019).

United States House of Representatives: Subcommittee on Health, of the Committee on Energy and Commerce. (2018). Better Data and Better Outcomes: Reducing Maternal Mortality in the U.S. Testimony Given on September 23, 2018. Avaliable online at: https://www.govinfo.gov/content/pkg/ CHRG-115hhrg36730/pdf/CHRG-115hhrg36730.pdf (accessed December 22, 2019).

Washington, H. A. (2006). Medical Apartheid: The Dark History of Medical Experimentation on Black Americans from Colonial Times to the Present. New York, NY: Doubleday, 2006.

Weir, R., Browne, G., Tunks, E., Gafni, A., and Roberts, J. (1996). Gender differences in psychosocial adjustment to chronic pain and expenditures for health care services used. Clin. J. Pain 12, 277-290. doi: 10.1097/00002508-199612000-00007

Weisse, C. S., Sorum, P. C., and Dominguez, R. E. (2003). The influence of gender and race on physicians' pain management decisions. J. Pain 4, 505-510. doi: 10.1016/j.jpain.2003.08.002

Zopf, Y., Rabe, C., Neubert, A., Janson, C., Brune, K., Hahn, E. G., et al. (2009). Gender-based differences in drug prescription: relation to adverse drug reactions. Pharmacology 84, 333-339. doi: 10.1159/000248311

Conflict of Interest: The authors declare that the research was conducted in the absence of any commercial or financial relationships that could be construed as a potential conflict of interest.

Copyright (c) 2020 Taylor and Glowacki. This is an open-access article distributed under the terms of the Creative Commons Attribution License (CC BY). The use, distribution or reproduction in other forums is permitted, provided the original author(s) and the copyright owner(s) are credited and that the original publication in this journal is cited, in accordance with accepted academic practice. No use, distribution or reproduction is permitted which does not comply with these terms. 